\title{
Studies in Acute Iron Poisoning III. The Hemodynamic Alterations in Acute Experimental Iron Poisoning
}

\author{
C.F.WhrtTen ${ }^{[14]}$, Y.G. CHen and G.W. Gibson \\ Department of Pediatrics, Wayne State University School of Medicine, and \\ the Children's Hospital of Michigan, Detroit, Michigan, USA
}

Extract

One hour after administration of a lethal dose of ferrous sulfate into the intestine, 10 dogs sustained a sharp decline in cardiac output (mean $57 \%$ ), a lesser reduction of arterial blood pressure (mean $17 \%$ ), and a marked elevation of total peripheral resistance (mean 100\%). Thereafter, the cardiac output decreased more rapidly than did blood pressure. Total peripheral resistance remained elevated until death.

Only minimal reduction in total blood volume (mean $9 \%$ ) was observed one hour after challenge, but the plasma volume was significantly reduced $(24 \%)$. Largely as a result of the reduction in plasma volume, the total blood volume was $70 \%$ of the baseline level just before death.

\section{Speculation}

It is unlikely that the simple early restoration of blood volume through plasma or plasma expanders would significantly alter the mortality in dogs poisoned with an $\mathrm{LD}_{100}$ dose of iron. This approach, however, could enhance the effectiveness of therapy with the promising chelating agent desferrioxamine. Desferrioxamine promotes the excretion of iron via the kidney. Early correction of blood volume deficits might maintain renal function for a sufficient length of time to permit excretion of critical quantities of iron.

Introduction

The pathophysiologic disturbances in acute iron poisoning are due to the effect of absorbed iron [7]. Shock is the major alteration induced by the absorbed iron [10]. This study was undertaken to determine the sequence and relative importance of the hemodynamic events which lead to the development of shock, since these aspects of acute iron poisoning have not been adequately investigated.

\section{Methods and Materials}

The subjects, 10 female mongrel dogs, were given water, but no food, for 24 hours prior to the study. Following anesthetization with sodium pentobarbital ( $30 \mathrm{mg} /$ $\mathrm{kg}$ body weight), iron poisoning was induced by the administration of an LD 100 dose of elemental iron, $225 \mathrm{mg} / \mathrm{kg}$ given as a $25 \%$ aqueous ferrous sulfate solution [10]. The solution was injected into the duodenum through a midline abdominal incision ( $7 \mathrm{dogs}$ ) or was 
instilled in the stomach through a Blakemore tube (3 dogs). The duodenal balloon of the Blakemore tube was inflated to prevent the loss of iron through vomiting. An endotracheal tube was inserted in the trachea to prevent aspiration. Urine was collected through an indwelling catheter in the bladder.

Polyethylene catheters were placed in the abdominal aorta (via a femoral artery), the inferior vena cava (via a femoral vein), and the portal vein (via a splenic vein) to permit constant monitoring of systemic blood pressure (BP), central venous, and portal vein pressures. These were measured and recorded with Statham transducers and a Gilson polygraph. Catheters were inserted via the other femoral artery and vein into the abdominal aorta and inferior vena cava to measure cardiac output. For each determination, $0.5-3.0 \mathrm{mg}$ of cardiogreen $(5 \mathrm{mg} / \mathrm{ml})$ was injected into the inferior vena cava. Blood was withdrawn from the aorta through a Waters densitometer by a Harvard constant infusion withdrawal pump, and dye curves were recorded on a Sargent recorder. The output was calculated according to the formula of Hetzel [5]. The total peripheral resistance was calculated from the formula [3]:

$$
\begin{gathered}
\text { Peripheral resistance units (PRU) }= \\
\frac{\text { mean arterial BP }(\mathrm{mm} \mathrm{Hg})}{\text { cardiac output }(\mathrm{ml} / \mathrm{s})}
\end{gathered}
$$

Plasma volume and red cell mass were determined simultaneously and independently by a double-labeling radioisotope dilution technique [2]. Plasma volume was determined by injecting $1 \mathrm{ml}$ of human serum albumin labeled with 2.0 microcuries of $I^{125}$. The red cell mass was determined by injecting $1 \mathrm{ml}$ of $\mathrm{dog}$ blood containing red cells labeled with $30 \mu \mathrm{c}$ of $\mathrm{Cr}^{51}$. A single blood sample was withdrawn 15-20 minutes after concomitant administration of the mixture of labeled substances. The measurements were made by use of a Volumetron, a semi-automatic electronic blood volume computer [12].

Arterial $\mathrm{pH}$ was measured with a Radiometer $\mathrm{pH}$ meter using a Sanz type electrode; for this, blood was collected anaerobically and placed on ice until analyzed. Concentrations of iron in serum and urine were determined by the methods of Goodwin [10]. Microhematocrit determinations were made with an International microhematocrit centrifuge.

Approximately $20 \mathrm{ml}$ of blood was removed each hour for making measurements, and this was replaced immediately with normal dog blood.

\section{Results}

An increase in serum iron concentration, a decrease in arterial $\mathrm{pH}$, and an increase in hematocrit were con- sistently present at one hour after challenge. Progressive changes in the same direction usually continued until death occurred at 3 to $9 \frac{1 / 2}{2}$ hours (table I). Severe oliguria developed in 8 of the 10 dogs. These features were consistent with the course of acute iron poisoning as previously described $[7,8,10]$.

\section{Cardiac Output, Total Peripheral Resistance, and Mean Arterial BP}

At one hour after the injection of iron there was a sharp decline in cardiac output (mean $57 \%$ ), a less severe reduction in mean arterial $\mathrm{BP}$ (mean $17 \%$ with virtually no change in $3 \mathrm{dogs}$ ), and a marked elevation in total peripheral resistance (mean $100 \%$ ) (tables III and IV).

Subsequently, the fall in BP did not parallel the decrease in cardiac output and moderately high BP readings were obtained until approximately one-half hour before death. The last values for cardiac output measured approximately one hour before death were less than $25 \%$ of the prechallenge level. Total peripheral resistance was elevated throughout the period of observation.

\section{Central Venous and Portal Vein Pressures}

Alterations in central venous pressure at one hour (8 animals) were variable. In four animals, no change occurred; in others, there was a decrease of 23-63\%. Subsequently, the former group showed little change, but the pressure in the latter group returned approximately to baseline levels.

The changes in portal vein pressure (6 animals) were also inconsistent. In five animals, there was a significant rise at one hour (mean $36 \%$ ) and a subsequent return to near normal levels at the time of the last determinations. In one animal, there was a slight fall at one hour. The final determinations were slightly higher than the baseline values in two and slightly lower in four dogs (tables III and IV).

\section{Plasma Volume, Red Cell Mass, and Total Blood Volume}

When measured at one hour, plasma volume decreased (mean $24 \%$ ). Serial determinations revealed a progressive decline, and the last analysis showed a volume less than $50 \%$ of the prechallenge level in 7 of the 10 animals. The changes in red cell mass were less marked. There was a slight to moderate increase at one hour and subsequently a return to values similar to or below control levels. With one exception, the algebraic sum of plasma volume and red cell mass (total blood volume) was moderately decreased at one hour (mean $9 \%$ ). Serial determinations indicated further reductions and the average preterminal deficit was approximately $30 \%$. 
Table $I$. Selected data on animals subjected to acute iron poisoning

\begin{tabular}{|c|c|c|c|c|c|c|c|c|c|c|c|c|c|c|c|c|c|c|c|c|c|c|c|c|c|}
\hline \multirow{3}{*}{$\begin{array}{l}\text { Dog } \\
\text { No. }\end{array}$} & \multirow{3}{*}{$\begin{array}{c}\text { Weight } \\
\mathrm{kg}\end{array}$} & \multirow{3}{*}{$\begin{array}{c}\text { Time of } \\
\text { death } \\
h\end{array}$} & \multirow{3}{*}{$\begin{array}{l}\text { Urine }^{1} \\
\mathrm{ml}\end{array}$} & \multirow{3}{*}{$\begin{array}{l}\text { Iron }^{2} \\
\text { mg }\end{array}$} & \multicolumn{8}{|c|}{ Serum iron $\mathrm{mg} \%$} & \multicolumn{8}{|c|}{ Arterial pH } & \multicolumn{5}{|c|}{ Hematocrit (vol. \%) } \\
\hline & & & & & & & & & & & & & \multicolumn{8}{|c|}{ Hours after injection of iron } & & & & & \\
\hline & & & & & 0 & 1 & 2 & 3 & 4 & 5 & 6 & $\overline{8}$ & 0 & 1 & 2 & 3 & 6 & 5 & 6 & $\overline{8}$ & $0 \quad 1$ & 2 & 3 & 4 & 568 \\
\hline 1 & 20.7 & $63 / 4$ & & & 0.13 & 7.6 & 9.4 & 11.1 & 11.1 & & & & 7.28 & 7.13 & 7.06 & & 7.07 & 6.93 & & & 4564 & 70 & & & 73 \\
\hline 2 & 16.0 & 3 & 1 & & 0.12 & 2.4 & & 5.3 & & & & & 7.30 & 7.22 & & 6.95 & & & & & 4355 & & 55 & & \\
\hline 3 & 12.5 & $51 / 2$ & 37 & 1.1 & 0.08 & 4.4 & 12.4 & 15.5 & 15.5 & 16.5 & & & 7.35 & 7.35 & 7.31 & 7.18 & 7.16 & 7.09 & & & 4556 & 69 & & 71 & \\
\hline 4 & 12.5 & 4 & 5 & 0.05 & 0.80 & 6.5 & 5.1 & 7.0 & 6.5 & & & & 7.35 & 7.27 & 7.16 & 7.06 & 6.80 & & & & 5768 & 71 & & 70 & \\
\hline 5 & 11.6 & 5 & 12 & 0.05 & & 1.0 & 1.5 & 8.8 & 10.6 & & & & 7.22 & 7.19 & 7.24 & 7.16 & 7.11 & & & & $46 \quad 62$ & 66 & 69 & & \\
\hline 6 & 15.0 & 4 & & & 0.15 & 6.9 & 8.1 & 8.4 & 8.4 & & & & 7.32 & 7.25 & 7.22 & 7.13 & & & & & 4961 & 686 & 67 & & \\
\hline 7 & 20.4 & 5 & 76 & 7.2 & 0.18 & 2.1 & 4.5 & 11.7 & 12.1 & 14.1 & & & 7.37 & 7.32 & 7.18 & 7.16 & 7.14 & & & & 5062 & 657 & 70 & & 77 \\
\hline 8 & 11.1 & $31 / 2$ & 9 & 0.03 & 0.12 & 5.5 & 10.0 & 13.1 & & & & & 7.37 & 7.34 & 7.14 & 7.03 & & & & & 5058 & 66 & 60 & & \\
\hline 9 & 16.0 & $91 / 2$ & & & 0.09 & 5.1 & 9.3 & 8.9 & 9.3 & 7.5 & 7.5 & 5.5 & 7.45 & 7.23 & 7.20 & 7.18 & 7.17 & 7.13 & 7.18 & 7.07 & 4366 & 707 & 74 & 757 & 75 \\
\hline 10 & 15.0 & $63 / 4$ & & & 0.12 & 2.8 & 11.0 & 12.1 & 10.0 & 9.6 & 7.9 & & 7.32 & 7.29 & 7.15 & 7.16 & 7.09 & 6.93 & 7.00 & & 4460 & 636 & & 646 & 6465 \\
\hline
\end{tabular}

Table II. Changes in blood volume during acute iron poisoning

\begin{tabular}{|c|c|c|c|c|c|c|c|c|c|c|c|c|c|c|c|c|c|c|c|c|c|c|c|c|}
\hline \multirow{3}{*}{$\begin{array}{l}\text { Dog } \\
\text { No. }\end{array}$} & \multicolumn{8}{|c|}{ Red cell mass (ml) } & \multirow{2}{*}{\multicolumn{8}{|c|}{$\frac{\text { Plasma volume }(\mathrm{ml})}{\text { Hours after injection of iron }}$}} & \multicolumn{8}{|c|}{ Total blood volume (mI) } \\
\hline & \multirow[b]{2}{*}{0} & \multirow[b]{2}{*}{1} & \multirow[b]{2}{*}{2} & \multirow[b]{2}{*}{3} & \multirow[b]{2}{*}{4} & \multirow[b]{2}{*}{5} & \multirow[b]{2}{*}{6} & \multirow[b]{2}{*}{8} & & & & & & & & & & & & & & & & \\
\hline & & & & & & & & & 0 & 1 & 2 & 3 & 4 & 5 & 6 & $\overline{8}$ & 0 & 1 & 2 & 3 & 4 & 5 & 6 & 8 \\
\hline 1 & 625 & 736 & & & 731 & & 690 & & 945 & 610 & & & 507 & & 418 & & 1570 & 1346 & & 1238 & & & & \\
\hline 2 & & & 677 & & & & & & 735 & 467 & & & & & & & & 1144 & & & & & & \\
\hline 3 & 405 & 424 & 518 & & & 402 & & & 625 & 505 & 340 & & & 235 & & & 1030 & 929 & 858 & & & 637 & & \\
\hline 4 & 482 & 484 & & 302 & & & & & 450 & 360 & & 190 & & & & & 932 & 848 & & 492 & & & & \\
\hline 5 & 520 & 587 & 535 & 505 & 521 & & & & 535 & 402 & 355 & 335 & 265 & & & & 1050 & 989 & 890 & 840 & 786 & & & \\
\hline 6 & 590 & 570 & 481 & & & & & & 558 & 435 & 352 & & & & & & 1148 & 1005 & 833 & & & & & \\
\hline 7 & 840 & 955 & 923 & 847 & 676 & & & & 898 & 715 & 680 & 667 & 590 & & & & 1738 & 1670 & 1603 & 1514 & 1266 & & & \\
\hline 8 & 335 & 377 & 380 & & & & & & 495 & 377 & 290 & & & & & & 830 & 754 & 670 & & & & & \\
\hline 9 & 651 & 735 & 605 & 637 & 667 & 570 & & & 747 & 662 & 457 & 510 & 617 & 445 & & 421 & 1398 & 1397 & 1062 & 1147 & 1284 & 1015 & & \\
\hline 10 & 630 & 711 & 673 & 673 & 581 & 587 & & & 640 & 460 & 415 & 382 & 333 & 322 & & & 1270 & 1170 & 1088 & 1055 & 914 & 809 & & \\
\hline
\end{tabular}


Table III. Hemodynamic changes in acute iron poisoning

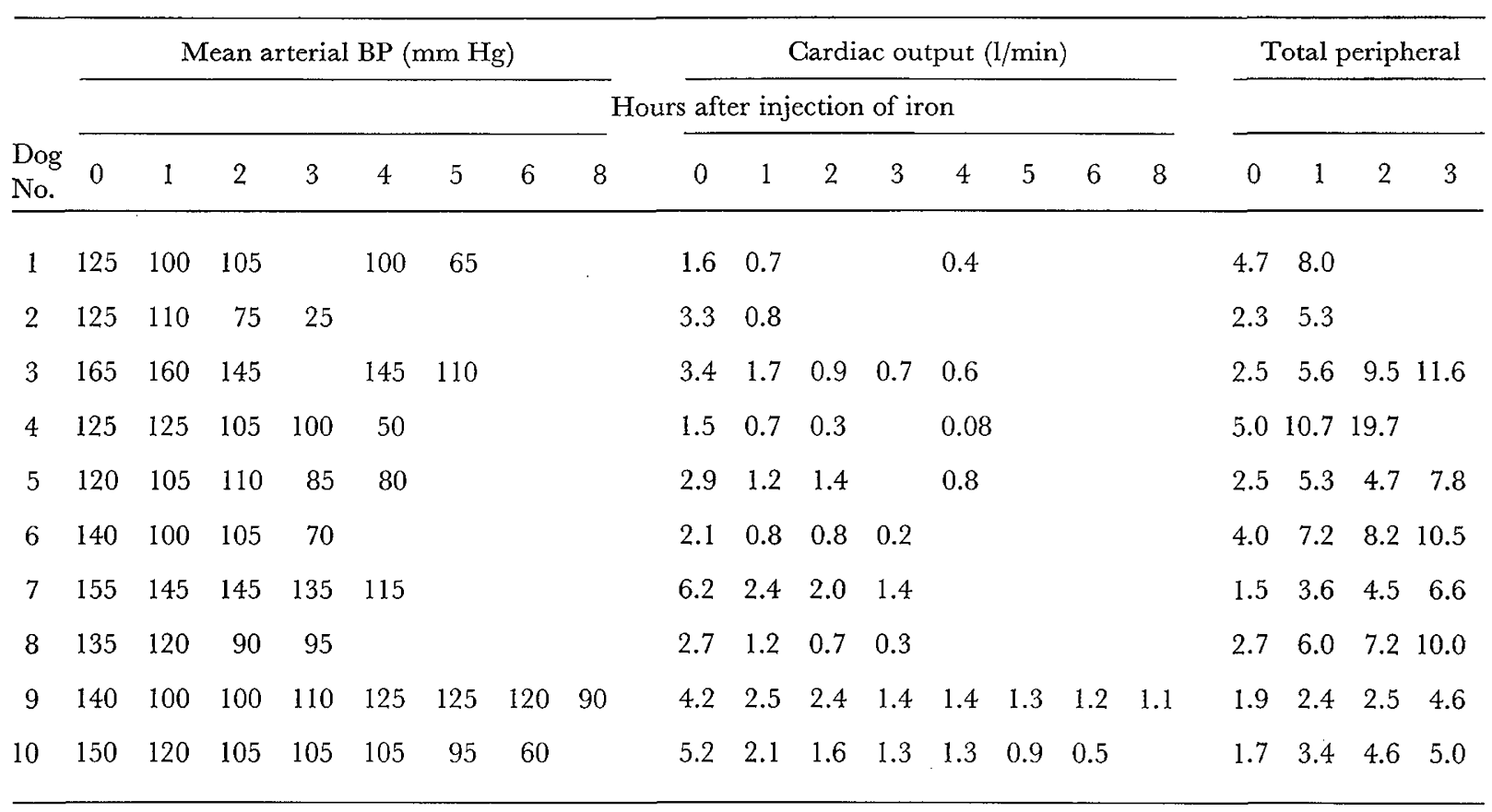
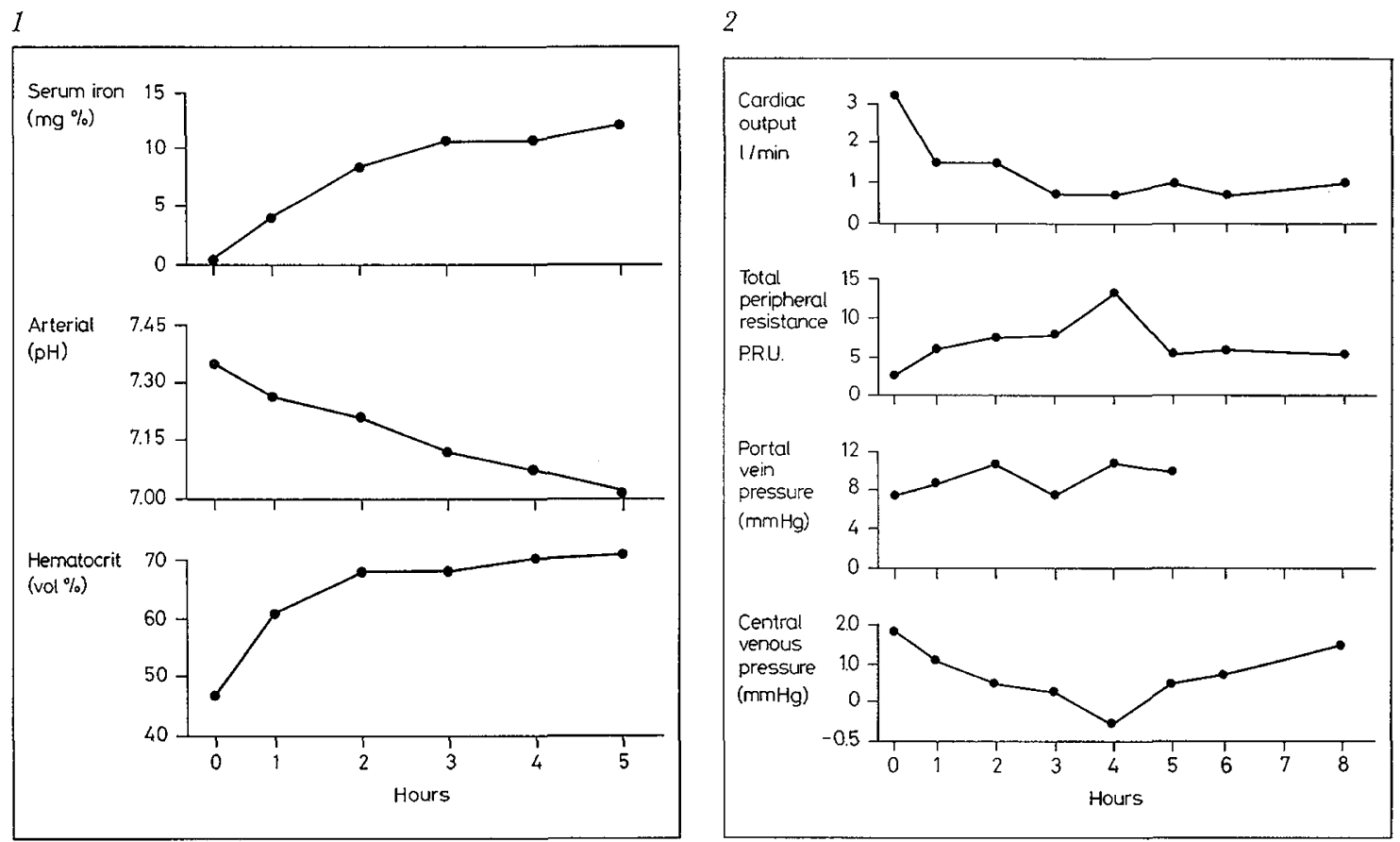

Figs. 1-3. Mean values measured during the course of iron poisoning. 


\begin{tabular}{|c|c|c|c|c|c|c|c|c|c|c|c|c|c|c|c|c|c|c|c|}
\hline \multicolumn{4}{|c|}{ resistance (PRU) } & \multicolumn{8}{|c|}{ Portal vein pressure $(\mathrm{mm} \mathrm{Hg})$} & \multicolumn{8}{|c|}{ Central vein pressure $(\mathrm{mm} \mathrm{Hg})$} \\
\hline \multirow[b]{2}{*}{4} & \multirow[b]{2}{*}{5} & \multirow[b]{2}{*}{6} & \multirow[b]{2}{*}{8} & \multicolumn{8}{|c|}{ Hours after injection of iron } & \multirow[b]{2}{*}{0} & \multirow[b]{2}{*}{1} & \multirow[b]{2}{*}{2} & \multirow[b]{2}{*}{3} & \multirow[b]{2}{*}{4} & \multirow[b]{2}{*}{5} & \multirow[b]{2}{*}{6} & \multirow[b]{2}{*}{8} \\
\hline & & & & 0 & 1 & 2 & 3 & 4 & 5 & 6 & 8 & & & & & & & & \\
\hline \multirow[t]{2}{*}{16.7} & & & & 7.4 & 9.3 & & & 10.7 & 9.6 & 5.9 & & 5.2 & 3.0 & & & 3.0 & 4.1 & 3.7 & \\
\hline & & & & 8.1 & 8.9 & & 5.9 & & & & & 4.4 & 3.3 & & 4.4 & & & & \\
\hline 15.5 & & & & 11.5 & 10.0 & 13.0 & 11.1 & & 10.7 & & & 1.9 & 0.7 & 1.9 & & & & & \\
\hline 37.5 & & & & 8.1 & 10.7 & 12.6 & & 10.7 & & & & & & & & & & & \\
\hline \multirow[t]{4}{*}{5.8} & & & & 6.7 & 12.0 & 11.1 & 11.5 & 8.9 & & & & 0.4 & 0.4 & 0.4 & -1.1 & -1.5 & & & \\
\hline & & & & 3.7 & 0.4 & 6.7 & 0.4 & & & & & 0.7 & 0.7 & 0.4 & 1.5 & & & & \\
\hline & & & & & & & & & & & & & 1.0 & -1.1 & -1.1 & & & & \\
\hline & & & & & & & & & & & & -3 & -3 & -3 & -3.3 & & & & \\
\hline 5.1 & 6.0 & 6.0 & 4.9 & & & & & & & & & 1.8 & 1.8 & 1.8 & 1.5 & -1.8 & -1.5 & 0.7 & 1.5 \\
\hline 4.8 & 4.8 & 6.1 & 6.1 & & & & & & & & & 1.1 & 0.7 & 0.4 & & -0.7 & -1.1 & -1.8 & \\
\hline
\end{tabular}

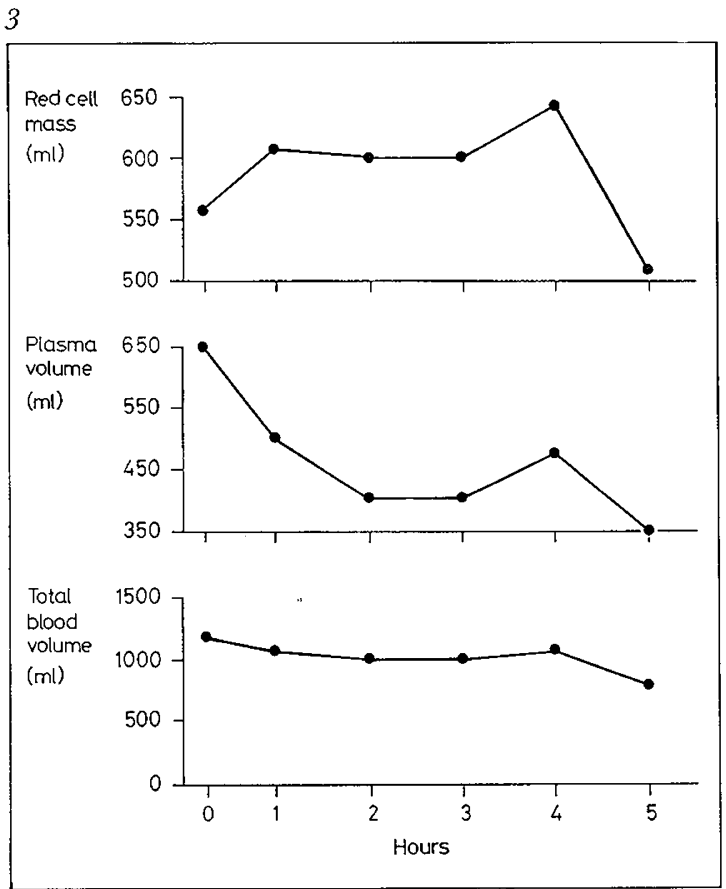

Serial values for the ratio of the peripheral circulation hematocrit (obtained from independent measurement of the plasma volume and red cell mass) to the large vessel hematocrit (obtained from measurement of the hematocrit of venous blood) are presented in table V. Shifts occurred throughout the course of iron poisoning.

Figures 1, 2 and 3 depict hourly mean values of all parameters monitored in the study. The purpose of presenting the material in graphic form is to indicate trends. The graphs should not be used to ascertain the precise changes at given times because, in some instances, data are available on only a few animals (tables I, II and III). 
Table IV. Alterations in circulation one hour after iron challenge (percent change from normal)

\begin{tabular}{|c|c|c|c|c|c|c|c|c|}
\hline $\begin{array}{l}\text { Dog } \\
\text { No. }\end{array}$ & $\begin{array}{c}\text { Cardiac } \\
\text { output }\end{array}$ & $\begin{array}{c}\text { Mean } \\
\text { arterial } \\
\text { blood }\end{array}$ & $\begin{array}{l}\text { Total } \\
\text { peripheral } \\
\text { resistance }\end{array}$ & $\begin{array}{c}\text { Portal } \\
\text { vein } \\
\text { pressure }\end{array}$ & $\begin{array}{c}\text { Central } \\
\text { vein } \\
\text { pressure }\end{array}$ & $\begin{array}{c}\text { Red } \\
\text { cell mass }\end{array}$ & $\begin{array}{l}\text { Plasma } \\
\text { volume }\end{array}$ & $\begin{array}{c}\text { Total } \\
\text { blood } \\
\text { volume }\end{array}$ \\
\hline 1 & -53 & -20 & +70 & +26 & -42 & +18 & -35 & -14 \\
\hline 2 & -75 & -40 & +130 & +10 & -23 & & -36 & \\
\hline 3 & -57 & -3 & +124 & -13 & -63 & +5 & -19 & -10 \\
\hline 4 & -54 & & +114 & +32 & & & -20 & -9 \\
\hline 5 & -59 & -15 & +112 & +79 & & +13 & -25 & -6 \\
\hline 6 & -61 & -29 & +80 & +81 & & -3 & -22 & -12 \\
\hline 7 & -58 & -3 & +125 & & & +3 & -20 & -10 \\
\hline 8 & -56 & -11 & +122 & & & +13 & -24 & -9 \\
\hline 9 & -60 & -20 & +100 & & -36 & +13 & -28 & -8 \\
\hline 10 & -41 & -29 & +26 & & & +13 & -12 & \\
\hline \multirow[t]{2}{*}{ Range } & -41 & 0 & +26 & +10 & 0 & -3 & -12 & 0 \\
\hline & to -75 & to -40 & to +130 & to +81 & to -63 & to +18 & to -36 & to -14 \\
\hline Mean & -57 & -17 & +100 & +36 & -21 & +8 & -24 & -9 \\
\hline
\end{tabular}

Table V. Ratio of overall body hematocrit to venous hematocrit

\begin{tabular}{rccccccc}
\hline Dog & \multicolumn{7}{c}{ Hours after iron poisoning } \\
\cline { 2 - 7 } No. & 0 & 1 & 2 & 3 & 4 & 5 & 0.881 \\
\hline 1 & 0.895 & 0.852 & & 0.843 & & \\
2 & & & 0.826 & & & \\
3 & 0.871 & 0.816 & 0.869 & & & \\
4 & 0.912 & 0.841 & & 0.893 & & \\
5 & & 0.956 & 0.909 & 0.870 & 1.027 & & \\
6 & 0.934 & 0.853 & & & \\
7 & 0.972 & 0.921 & 0.880 & 0.800 & 0.720 & & \\
8 & 0.810 & 0.862 & 0.862 & & & \\
9 & & 0.915 & 0.886 & 0.932 & 0.851 & 0.967 & \\
10 & & 0.897 & 0.905 & 0.84 & 0.813 & 0.875 \\
\hline
\end{tabular}

\section{Discussion}

Reismann and Coleman [7] presented data on the hemodynamic status of one dog with acute iron poisoning and stated that it was representative of data on three animals. They assumed that the early onset of acidosis in that dog was not related to tissue hypoxia because the cardiac output was not altered at two hours. In each of the 10 dogs we studied, however, we found marked reduction in cardiac output at one hour. Thus, tissue anoxia does provide a satisfactory explanation for the acidosis. Poor tissue perfusion leads to tissue anoxia, anaerobic metabolism, and an accumulation of lactate [6]. Theoretically, decreases in cardiac output can be ascribed to: (a) cardiac failure; (b) a decrease in total blood volume; or, (c) a decrease in effective circulating blood volume [1]. Congestive heart failure was probably not present because the central venous pressure was not elevated. There was a diminution in total blood volume, but the magnitude was too small to account for the degree of alteration in cardiac output. Thus, the early decrease in cardiac output appeared to reflect a reduction in the effective circulating blood volume, presumably from venous pooling.

Although there was no significant early change, there was a progressive reduction in total blood volume which contributed to the late decline in cardiac output. The magnitude of the reduction in blood volume in fatal iron poisoning has not been assessed previously. The only published data on changes of blood volume were obtained during the course of three nonlethal poisonings [7]. Several investigators have indicated 
that blood volume studies in dogs are reliable only when red cell mass and plasma volume are measured simultaneously and independently $[1,2,4]$. GRABLE et al. [2] utilized this type of monitoring in a study of hemorrhagic and endotoxic shock and did not find a significant preterminal deficit in total blood volume (mean $7 \%$ ). Through the use of this technique, the preterminal deficit in total blood volume in our $10 \mathrm{dogs}$ with acute iron poisoning averaged $30 \%$. The deficit was primarily the result of a decrease in plasma volume. The mechanism responsible for the reduction in plasma volume in hemorrhagic and endotoxic shock is assumed to be a loss of plasma due to increased intracapillary pressure (capillary stasis) [2]. The magnitude of the change in plasma volume found in dogs with iron poisoning was considerably greater than the loss associated with capillary stasis [2] and suggests the presence of increased capillary permeability unrelated to pressure changes. Elevated levels of vasoactive substances (serotonin and histamine) in plasma have been detected during acute experimental iron poisoning [11] and these substances could produce an increase in capillary permeability. This increase could also be the result of direct contact of iron with blood vessels which can cause cellular injury, for iron particles have been found in the lumen of intestinal vessels of iron poisoned animals $[8,9,10]$.

An increase in the peripheral circulation hematocrit was observed in this study. As hemoconcentration occurs, viscosity is increased and resistance to flow elevated. To what extent these factors played a role in the reduction in cardiac output cannot be estimated because the dynamic relations between myocardial capacity, viscosity, peripheral resistance, and blood flow have not been established in intact animals.

Although shock is a cardinal feature of fatal acute iron poisoning in children, no hemodynamic data obtained on children during acute iron poisoning have been published. Whether the observations made on dogs would apply precisely to children is unknown. One important difference probably exists. In unsplenectomized dogs in shock or in impending shock, there is an influx of blood with a high hematocrit from the spleen. To some extent, the increment in large vessel hematocrit in dogs is the result of this factor. In humans, this mechanism is not operative to any significant degree. Thus, the reduction in total blood volume in children might be far greater than that found in dogs.

Until data on humans are available, therapy must be based upon information gained from animals studied under experimental conditions. This study suggests that the need to restore effective blood volume occurs early in the course of fatal iron poisoning and that the presence of this need cannot be predicted by measuring changes in arterial blood pressure.

33 Pediat. Res., Vol. 2, No. 6 (1968)
References and Notes

1. Gilbert, R.P.: Mechanisms of the hemodynamic effects of endotoxin. Physiol. Rev. 40: 245 (1960).

2. Grable, E.; Israel, J.; Williams, J. A. and Fine, $\mathrm{J}$.: Blood volumes in experimental endotoxic and hemorrhagic shock. Ann. Surg. 157: 361 (1963).

3. GREen, H.O.: Analysis of cardiovascular activity; in Methods in medical research (ed. PotTer, V.R.), vol.1, p.243. (Yearbook, Chicago 1948).

4. Gregerson, M.J. and Rawson, R.A.: Blood volume. Physiol. Rev. 39: 307 (1959).

5. Hetzel, P.S.; Mankin, H.T.; Swan, H.J. G. and Woon, E.H.: Abstracts of communications. XIX Int. Physiol. Congr., Montreal 1953, p. 461.

6. Levenson, S.M.; NAgler, A.L. and Einheber, A.: Some metabolic sequences of shock; in Shock (ed. Hershey, S.G.), p.79 (Little Brown, Boston 1964).

7. Reismann, K. R. and Coleman, T.J. : Acute intestinal iron intoxication: II. Metabolic, respiratory, and circulatory effects of absorbed iron salts. Blood 10: 46 (1955).

8. Reismann, K.R.; Coleman, T.J.; Budai, B.S. and MorIARITY, L.R.: Acute intestinal iron intoxication: I. Iron absorption, serum iron, and autopsy findings. Blood 10: 35 (1955).

9. Smith, R.P.; Jones, C.W. and Cochran, W.E.: Ferrous sulphate toxicity. Report of a fatal case. New Engl.J. Med. 243: 641 (1950).

10. Whirten, C.F.; Gibson, G.W.; Good, M.H.; Goodwin, J.F. and Brough, A.J. : Studies in acute iron poisoning: I. Desferioxamine in the treatment of acute iron poisoning: Clinical observations, experimental studies, and theoretical considerations. Pediatrics 36: 322 (1965).

11. Whirten, C.F.: Unpublished observations.

12. Williams, J.A. and Fine, J.: Measurements of blood volume with a new apparatus. New Engl.J. Med. 263: 842 (1961).

13. This investigation was supported by Public Health Service Grant No.FR-74, from the General Clinical Research Centers Branch of the Division of Research Facilities and Resources, and Public Health Service Research Grant No. GM 0903601Al from the Research Grants Branch of the National Institute of General Medical Sciences.

14. Requests for reprints should be addressed to: C.F. Whitren, M.D. General Clinical Research Center for Children, Children's Hospital of Michigan, 5224 St. Antoine, Detroit, Mich. 48202 (USA). 